\title{
Farmer Preference of Cassava Cultivars in Eastern Uganda: A Choice Beyond Disease Resistance
}

\author{
Faizo Kasule ${ }^{1}$, Peter Wasswa ${ }^{1}$, Settumba Brasio Mukasa ${ }^{1}$, Anthony Okiror $^{1}$, Selma Ndapewa Nghituwamhata ${ }^{1}$, \\ Evalyne Chepkoech Rono ${ }^{1}$, Clever Mukuze ${ }^{1} \&$ Agnes Wakesho Mwang'ombe ${ }^{2}$ \\ ${ }^{1}$ College of Agricultural and Environmental Sciences, Department of Agricultural Production, Makerere \\ University, P. O. Box 7062, Kampala, Uganda \\ ${ }^{2}$ Department of Plant Science and Crop Protection, University of Nairobi, P.O. Box 30197-00100, Nairobi, \\ Kenya \\ Correspondence: Faizo Kasule, College of Agricultural and Environmental Sciences, Department of Agricultural \\ Production, Makerere University, Kampala, Uganda. Tel: 256-702-018-571. E-mail: kfay337@gmail.com
}

Received: August 20, 2020 Accepted: September 1, 2020 Published: December 2, 2020

\begin{abstract}
The cassava breeding program in Uganda has released many improved cultivars resistant/tolerant to cassava brown streak disease (CBSD) and cassava mosaic disease (CMD). However, many farmers have continued to use cultivars that are susceptible to these major viral diseases but with diverse attributes. There is a need to understand farmers' cassava cultivar attribute preferences and CBSD, CMD prevalence on the preferred cultivars. A total of 150 cassava farmer fields (74 in Bukedea district and 76 in Kumi district) located in eastern Uganda were evaluated for farmers' cultivars and attribute preferences, as well as prevalence of CBSD and CMD on the farmer selected cultivars. The eastern region was of interest in the study, due to it-being the major cassava producing area in the country. In addition, 30 cassava plants of different genotypes were chosen randomly along transects of each field and assessed for CBSD/CMD incidence and severity on preferred cultivars. Results showed that more than $64 \%$ of the farmers in eastern Uganda preferred NASE 03 due to its sweet taste and high yields, followed by NASE $14(21 \%)$ because of its high yields. There was a significant $(\mathrm{P} \leq 0.001)$ correlation between cassava cultivars preferred and CBSD severity $(r=-0.56)$, CBSD incidence $(r=-0.53)$, CMD severity $(r=-0.51)$ and CMD incidence $(r=-0.39)$. In corroboration, the most preferred cultivar, NASE 03 was found most susceptible to CBSD and CMD in both Bukedea and Kumi districts with CBSD incidence of $62.2 \%$ and $52.7 \%$ and CMD incidence of $56.9 \%$ and $34.3 \%$ respectively. The results showed that CBSD and CMD are prevalent on farmer preferred cassava cultivars, and that farmer cultivar preference depends not only on disease resistance but also other attributes.
\end{abstract}

Keywords: Cassava brown streak disease, cassava mosaic disease, preferred cassava cultivars, cassava attributes

\section{Introduction}

Cassava (Manihot esculenta Crantz) is an important staple food crop cultivated in many parts of Africa by more than 800 million people. In Uganda cassava is grown in all parts of the country, with eastern region being the major producer (FAOSTAT, 2017; UBOS, 2017). However, cassava production in Uganda is greatly constrained by a number of biotic factors. Of these, cassava brown streak disease (CBSD) caused by cassava brown streak viruses (CBSVs) and cassava mosaic disease (CMD) caused by different species of cassava mosaic geminiviruses (CMGs) are the major viral diseases leading to severe yield losses of up to 100\% (Legg et al., 2011; Legg et al., 2014).

The CBSVs and CMGs are transmitted by whitefly Bemisia tabaci Gennadius, and can also be spread through cuttings, which is exacerbated by the virtue that cassava is vegetatively propagated (Maruthi et al., 2005; Legg et al., 2015). The vegetative nature of cassava has made management of viral diseases difficult, as often cassava planting materials and the cyclic-propagation of field sourced planting materials in cassava leads to continued virus presence and build up in the environment (Maruthi et al., 2005; Legg et al., 2014).

Prevention of CBSD and CMD through breeding for resistance is the most sustainable strategy especially for the resource poor farmers. Many cassava cultivars have been released and adopted by farmers throughout Uganda, especially in the eastern region which is a major cassava producing area. Despite the efforts for CBSD and CMD prevention, these viral diseases are still prevalent in all agro-ecological zones in Uganda and most cassava fields usually have both diseases occurring on the same cassava plants at the same time and causing significant yield 
losses (Kawuki et al., 2017). Besides, resistant varieties are not the most preferred by farmers as they are deficient in some farmer preferred attributes; farmers in Uganda growing cassava prefer a diversifying approach to a directional selection of cassava varieties, keeping some low yielding and disease susceptible varieties but with sweet taste as it is beyond disease resistance when selecting cassava varieties for planting (Kawuki et al., 2017; Nakabonge et al., 2017).

Although the cassava breeding program in Uganda has developed and released the improved varieties with differential levels of viral disease resistance, these may not be attractive to local farmers unless they possess some specific attributes that farmers consider important. Some farmers in the country are still growing local cassava varieties despite the distribution of disease-tolerant and high yielding improved varieties. The duration of cassava cultivation in Uganda has evolved over time and undergone both environmental and human selection on farmers' fields. Ugandan farmers commonly grow NASE 1, TME 14, NASE 03, NASE 14, NASE 14, NASE 18, NASE 19, NAROCASS 1, NAROCASS 2 among others as improved varieties (Kawuki et al., 2017). Many local cassava varieties are also preferred by farmers in Uganda; Gbasumenge, Abiria, Mingoro varieties (Northwest), Kwatamumpale and Bukalasa varieties (Central), Magana and Ofumbachai varieties (Eastern), Nyaraboke and Timtim varieties (western Uganda) (Kawuki et al., 2017; Nakabonge et al., 2017). Cassava farmers in Uganda use clean planting material of their preferred but susceptible cultivars when establishing new fields, which are obtained from seed multiplication blocks that are $250 \mathrm{~m}$ away from other cassava fields (Kasule et al., 2020). It is also clear that farmers have preferences that influence the decisions taken to retain or abandon particular varieties (Nakabonge et al., 2017). The performance of many of these released cassava cultivars also deteriorates as viruses build up in the field sourced planting materials (Kawuki et al., 2016; McQuaid et al., 2016).

In order to design appropriate control measures for CBSD and CMD, prevalence of these diseases needs to be reassessed, especially on farmer preferred cultivars. Furthermore, periodic surveys help in providing information for establishing current CBSD and CMD prevalence, farmer preference attributes, deterioration in virus resistance and modelling disease behavior over time in farmer preferred cassava cultivars. Therefore, this study explores farmers' preference attributes for the different cassava cultivars and also determines CBSD and CMD prevalence on farmer preferred cassava cultivars in eastern Uganda.

\section{Materials and methods}

\subsection{Study Area}

The study was conducted in Bukedea and Kumi districts of eastern Uganda - being the major cassava producing area, in 2018 to determine farmers' preference attributes for the different cassava cultivars and CBSD and CMD prevalence on farmer preferred cassava cultivars. Bukedea is located between latitudes $1^{\circ} 20^{\prime} 30.60^{\prime \prime} \mathrm{N}$ and longitudes $34^{\circ} 02^{\prime} 24^{\prime \prime} \mathrm{E}$ and Kumi is located between latitudes $1^{\circ} 27^{\prime} 38^{\prime \prime} \mathrm{N}$ and longitudes $33^{\circ} 56^{\prime} 10^{\prime \prime} \mathrm{E}$.

\subsection{Sampling Frame}

The two districts were purposely selected because they are dominantly cassava growing areas in the region. A survey was conducted in the two districts targeting farmers growing cassava, therefore purposive simple random sampling was used. Each cassava farm evaluated was spaced at least $1 \mathrm{~km}$ from each other (Sseruwagi et al., 2004). A total of 150 cassava farmers were evaluated (74 in Bukedea district and 76 in Kumi district). Cassava fields between the ages of six months to two years were selected. Cassava fields in the sub-county (territorial division within a district) were used as the sampling frame. Overall, five sub-counties were sampled in Bukedea district (Malera, Kabarwa, Kidongole, Koena and Kocheka), where, the number of cassava fields sampled per sub-county were 20, 14, 17, 17, 6 respectively. In Kumi district, four sub-counties (Ongino, Kumi, Kanyum and Ngero) were surveyed and cassava fields sampled per sub-county were 20,15, 21 and 20 respectively.

\subsection{Data Collection}

Data were collected through observations and interviews with cassava farmers using a structured questionnaire to record variables which included; farmer attributes for cassava cultivar preference, preferred cultivars, $\mathrm{CBSD} / \mathrm{CMD}$ incidence and severity. Within each cassava field, 30 cassava plants of different genotypes were chosen randomly along transects of a field and assessed for farmer preference, CBSD/CMD incidence and severity. Each cassava plant was an observational unit and farmer preferred cultivars were noted. For CBSD severity, the assessment was done using foliar and stem symptoms, and was based on a scale of $1-5$ (Gondwe et al., 2003). Where $1=$ no apparent symptoms; 2 = slight foliar feathery chlorosis and no stem lesions; $3=$ pronounced foliar feathery chlorosis, mild stem lesions, and no dieback; 4 = severe foliar feathery chlorosis, severe stem lesions, and no dieback; and $5=$ defoliation, severe stem lesions, and dieback. 
CMD severity was assessed using a $1-5$ severity scale (IITA, 1990). Where $1=$ no symptoms observed (shoot healthy); 2 = mild chlorotic pattern on most leaves, mild distortions at the bases of most leaves, with the remaining parts of the leaves and leaflets appearing green and healthy; $3=$ a pronounced mosaic pattern on most leaves, with narrowing and distortion of the lower one-third of most leaves; $4=$ severe mosaic distortion of two-thirds of most leaves, with general reduction in leaf size and some stunting of shoots; and $5=$ very severe mosaic symptoms on all leaves, with distortion, twisting, and severe reduction in leaf size in most leaves, accompanied by severe stunting of plants. The CBSD and CMD incidence data were obtained from the number of plants showing foliar disease symptoms, expressed as a percentage of the total number of plants assessed for each district.

\subsection{Data Processing and Analyses}

The collected data on the CBSD and CMD severity, and farmer preferred cassava cultivars were subjected to analysis of variance using GenStat $14^{\text {th }}$ edition. Averages for preferred cassava cultivars were used to generate graphs using Microsoft excel (Microsoft corporation 2016) software. Comparisons of means were made using Fisher's protected least significant difference (LSD) at $\mathrm{P} \leq 0.05$. Correlation analysis using GenStat $14^{\text {th }}$ edition was also done to establish the relationship between farmer cultivar preference with CBSD and CMD prevalence, to assess virus presence on farmer preferred cultivars.

\section{Results}

3.1 Cassava Farmer Preference Attributes used in Selecting Preferred Cultivars in Bukedea and Kumi Districts of Eastern Uganda

From the survey, the farmers from eastern Uganda in both Bukedea and Kumi districts mostly preferred NASE 03, with percentage rating of $70.3 \%$ and $64.6 \%$ respectively followed by NASE 14 with $17.5 \%$ and $25 \%$ respectively (Figure 1). NAROCASS 1 was the least preferred in Bukedea with 2.7\% while NASE 19 was the least preferred in Kumi with $2.6 \%$ (Figure 1).

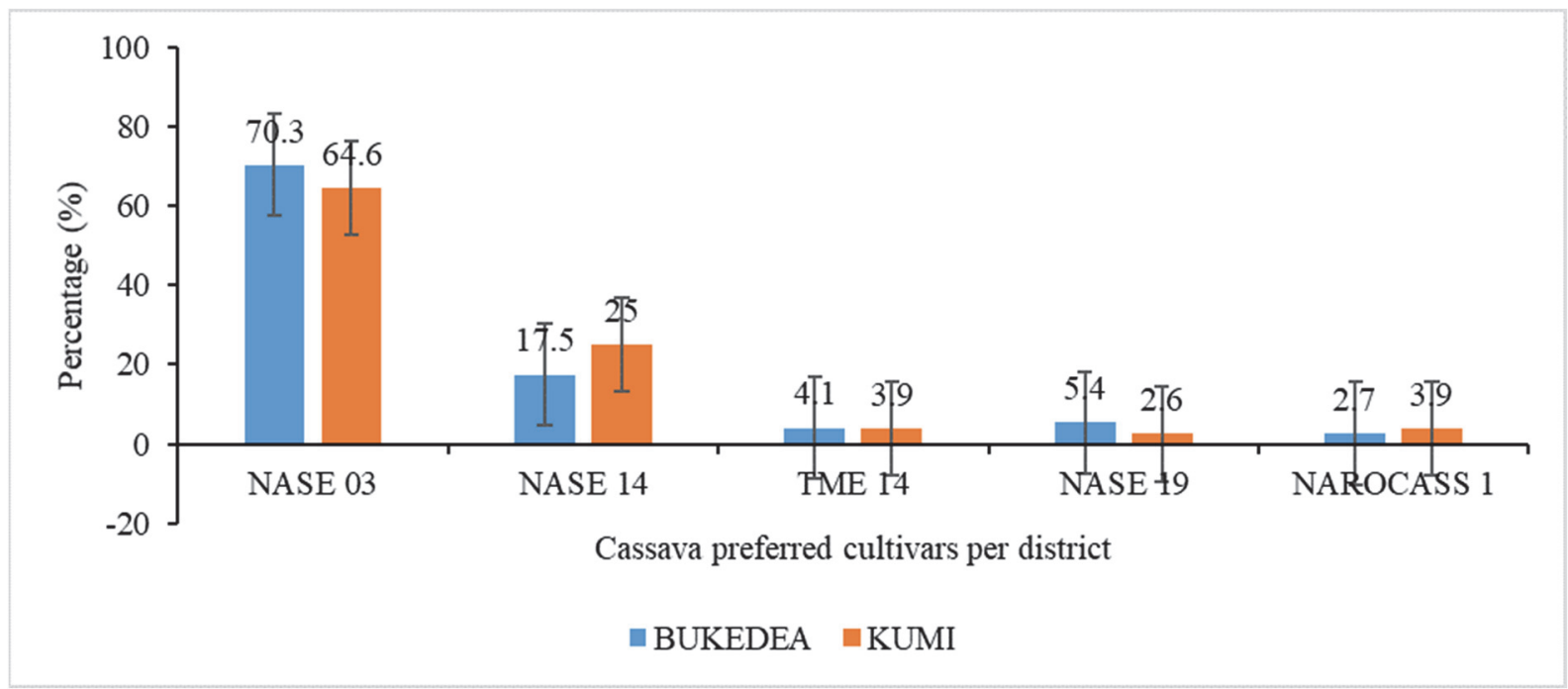

Figure 1. Cassava cultivars preferred by farmers in Bukedea (blue)and Kumi (orange) districts of eastern Uganda. NASE 03 was the most preferred followed by NASE 14 while NASE 19 and NAROCASS 1 were the least preferred

It was clear that farmers in Bukedea and Kumi districts preferred improved cassava cultivars basing mostly on attributes of sweet taste, good disease tolerance, good storability in the ground, high yields, early maturity among others (Table 1). The percentage for the different attributes farmers in eastern Uganda put into consideration when selecting cassava cultivars are shown in table 1. NASE 03 was mostly preferred because of sweet taste and high yielding attribute while NASE 14 was preferred because of high yielding and good disease resistance attributes (Table 1). 
Table 1. Attributes preferred by farmers for the different cassava cultivars in eastern Uganda

\begin{tabular}{llllll}
\hline \multirow{2}{*}{ Attribute } & \multicolumn{5}{l}{ Farmer preferred cassava cultivars in eastern Uganda } \\
\cline { 2 - 6 } & NASE 03 & NASE 14 & TME 14 & NASE 19 & NAROCASS 1 \\
\hline High yielding & 16.67 & 31.25 & 0 & 42.86 & 20 \\
Very good storability in the ground & 12.5 & 3.13 & 60 & 0 & 0 \\
Good cooking quality & 9.38 & 0 & 0 & 0 & 0 \\
Sweet taste & 26.04 & 12.5 & 0 & 0 & 0 \\
Very early maturing & 5.2 & 9.38 & 40 & 0 & 0 \\
Increased disease tolerance & 9.38 & 3.13 & 0 & 0 & 0 \\
Very good disease resistance & 2.08 & 21.87 & 0 & 57.14 & 80 \\
Good flour quality & 8.33 & 9.37 & 0 & 0 & 0 \\
Good Marketability & 10.42 & 9.37 & 0 & 0 & 0 \\
\hline
\end{tabular}

\subsection{Incidence and Severity for CBSD and CMD in Bukedea and Kumi Districts in Eastern Uganda}

CBSD and CMD were prevalent in all sub-counties in both Bukedea and Kumi districts (Table 2). The presence of CBSD and CMD were observed in the local cultivars/landraces and the improved cultivars. In both districts, dual infection with CBSD and CMD was observed. Mean CBSD severity was higher than that of CMD in both Bukedea and Kumi districts (Table 2). CBSD was severer in Bukedea than in Kumi with a mean severity of 3.2 compared to 3.0 respectively. CMD was also more severe in Bukedea with average severity score of 2.8 than in Kumi with average severity score of 2.5 (Table 2). Similarly, there was a high incidence of both CBSD and CMD in all sub-counties in both Bukedea and Kumi districts (Table 2). There was higher incidence of both CBSD and CMD in Bukedea than in Kumi district. The CBSD incidence was 53\% and $48.1 \%$ in Bukedea and Kumi respectively while the average CMD incidence was $43.9 \%$ and $29.8 \%$ in Bukedea and Kumi respectively (Table 2).

Table 2. Cassava brown streak disease and cassava mosaic disease foliar severity and incidence (\%) for the different sub counties surveyed in Bukedea and Kumi districts of eastern Uganda

\begin{tabular}{lllll}
\hline Bukedea sub counties & \multicolumn{2}{c}{ CBSD } & \multicolumn{2}{c}{ CMD } \\
\hline Malera & Severity & Incidence & Severity & Incidence \\
Kabarwa & 2.9 & 42.8 & 2.75 & 36.8 \\
Kidongole & 2.93 & 48.6 & 2.79 & 48.3 \\
Koena & 3.71 & 58.2 & 2.94 & 40.6 \\
Kocheka & 3.94 & 75.9 & 3.47 & 74.3 \\
Mean & 2.67 & 39.4 & 2.17 & 19.5 \\
LSD $(0.05)$ & 3.2 & 53 & 2.8 & 43.9 \\
CV $(\%)$ & 0.73 & 19.02 & 0.78 & 18.19 \\
Kumi sub counties & 23.7 & 37.7 & 28.6 & 41.3 \\
& CBSD & & & CMD \\
Ongino & Severity & Incidence & Severity & Incidence \\
Kumi & 3.2 & 50 & 2.45 & 27.3 \\
Kanyum & 2.93 & 50.2 & 2.47 & 29.6 \\
Ngero & 2.76 & 43 & 2.62 & 31.6 \\
Mean & 3.3 & 49 & 2.45 & 30.7 \\
\end{tabular}




\begin{tabular}{lllll}
$\operatorname{LSD}(0.05)$ & 0.55 & 13.03 & 0.56 & 13.85 \\
$\mathrm{CV}(\%)$ & 28.2 & 43.3 & 34.4 & 73.9 \\
\hline
\end{tabular}

$\mathrm{LSD}=$ the least significant difference at $\mathrm{P} \leq 0.05, \mathrm{CV}=$ the coefficient of variation

\subsection{CBSD and CMD Prevalence on Preferred Cassava Cultivars in Eastern Uganda}

Overall, there were significant differences $(\mathrm{P}<0.05)$ between preferred cassava cultivars for both CBSD and CMD severity and incidence in eastern Uganda (Table 3). Both CBSD and CMD were prevalent on farmer preferred cassava cultivars in eastern Uganda (Table 3). NASE 03 (the most preferred cultivar in both Bukedea and Kumi districts; Figure 1) had the highest CBSD severity score of 3.6 in Bukedea and 3.3 in Kumi, and highest CMD severity score of 3.3 in Bukedea and 2.8 in Kumi (Table 3). CBSD and CMD incidence were highest on NASE 03 in both Bukedea and Kumi with CBSD incidence of $62.2 \%$ and $52.7 \%$ respectively and CMD incidence of 56.2\% and $34.3 \%$ respectively (Table 3). NAROCASS 1 had the least CBSD and CMD incidence (0\%) (Table 3), although it was among the least preferred cultivars (Figure 1).

Table 3. Cassava brown streak disease and cassava mosaic disease foliar severity and incidence (\%) on preferred cassava cultivars in Bukedea and Kumi districts of eastern Uganda

\begin{tabular}{lllllllll}
\hline Cultivar & \multicolumn{3}{c}{ BUKEDEA } & \multicolumn{5}{c}{ KUMI } \\
\hline & \multicolumn{3}{c}{ CBSD } & & CMD & & \multicolumn{1}{c}{ CBSD } & CMD \\
& Severity & Incidence & Severity & Incidence & Severity & Incidence & Severity & Incidence \\
NAROCASS 1 & 1.0 & 0 & 1.0 & 0 & 1.0 & 0 & 1.0 & 0 \\
NASE 19 & 2.0 & 15.8 & 1.0 & 0 & 2.0 & 15 & 1.0 & 0 \\
TME 14 & 3.0 & 34.4 & 2.0 & 30 & 2.7 & 36.7 & 2.3 & 27.8 \\
NASE 14 & 2.8 & 47.9 & 1.0 & 0 & 2.5 & 35.4 & 1.0 & 0 \\
NASE 03 & 3.6 & 62.2 & 3.3 & 56.9 & 3.3 & 52.7 & 2.8 & 34.3 \\
Mean & 2.5 & 32.1 & 1.7 & 17.4 & 2.3 & 28 & 1.6 & 12.4 \\
LSD (0.05) & 1.01 & 26.61 & 0.89 & 28.62 & 0.86 & 20.84 & 0.9 & 24.78 \\
CV (\%) & 21.1 & 34 & 23.4 & 48.3 & 20.7 & 32.4 & 28.6 & 74.3 \\
\hline
\end{tabular}

$\mathrm{LSD}=$ the least significant difference at $\mathrm{P} \leq 0.05, \mathrm{CV}=$ the coefficient of variation

NAROCASS 1 was observed to have $0 \% \mathrm{CMD}$ and CBSD incidence even in situations where some farmers grew it in close proximity to very highly CMD and CBSD susceptible cultivars (Figure 2). There was a highly significant correlation between cassava cultivars preferred and CBSD severity $\left(\mathrm{r}=-0.56^{* * *}\right)$, CBSD incidence $\left(\mathrm{r}=-0.53^{* * *}\right)$, CMD severity $\left(\mathrm{r}=-0.51^{* * *}\right)$ and CMD incidence $\left(\mathrm{r}=-0.39^{* * *}\right)$ (Table 4$)$. 


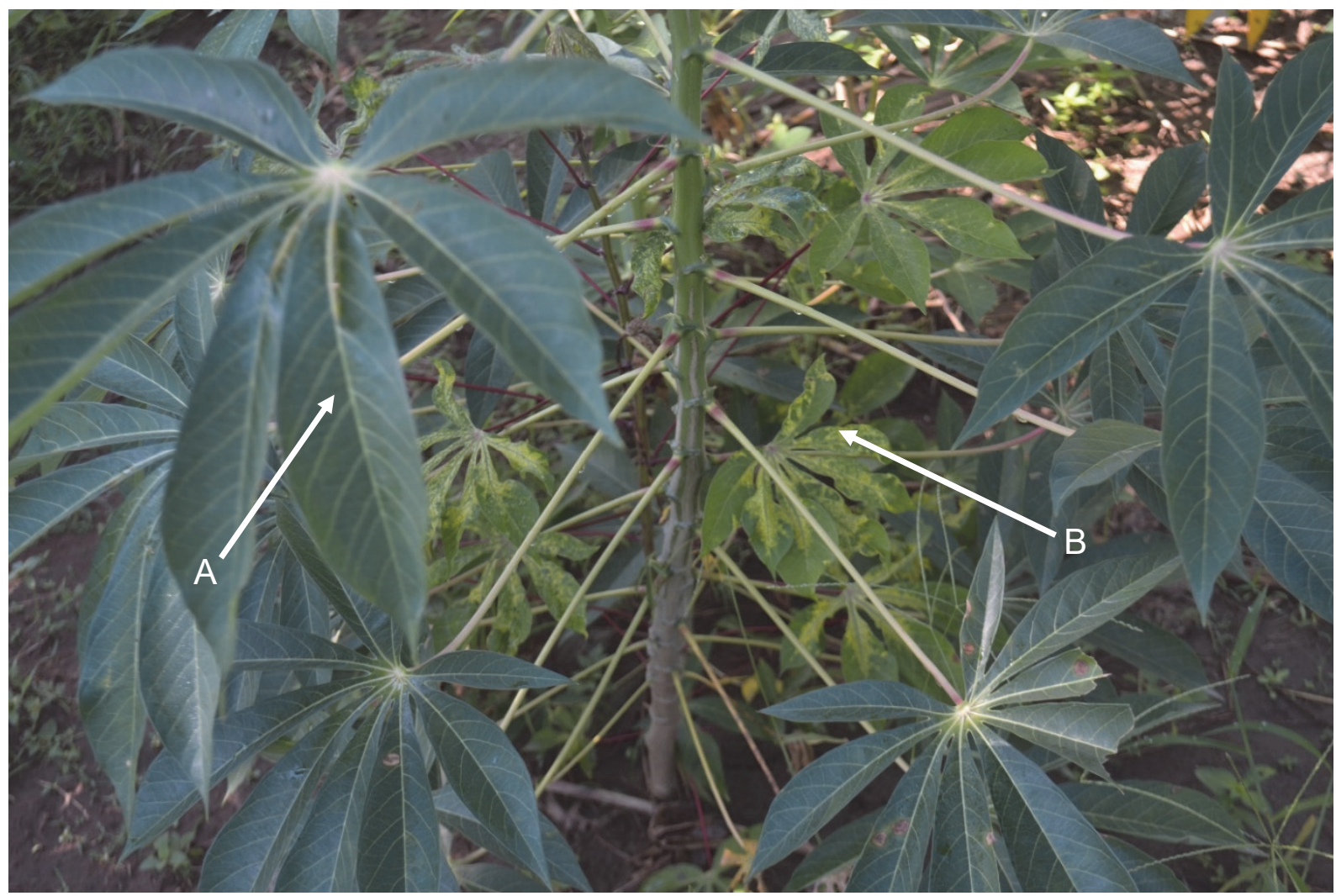

Figure 2. Unique observation in a farmer field in Bukedea district of eastern Uganda; where healthy NAROCASS 1 cultivar depicted as "A" is planted together with cassava brown streak disease and cassava mosaic disease infected NASE 03 cultivar as "B". NAROCASS 1 did not show any disease symptoms neither did it succumb to the two diseases, as was confirmed by PCR/RT-PCR

Table 1. Correlation coefficients between cassava brown streak disease/cassava mosaic disease severity, cassava brown streak disease/cassava mosaic disease incidence (\%) and cassava cultivar preferred for eastern Uganda

\begin{tabular}{llllll}
\hline & CBSD severity & CBSD incidence & CMD incidence & CMD severity & Cultivar preferred \\
\hline CBSD severity & 1 & & & & \\
CBSD incidence & $0.76^{* * *}$ & 1 & & & \\
CMD incidence & $0.43^{* * *}$ & $0.58^{* * *}$ & 1 & 1 & \\
CMD severity & $0.45^{* * *}$ & $0.52^{* * *}$ & $0.75^{* * *}$ & 1 & \\
Cultivar preferred & $-0.56^{* * *}$ & $-0.53^{* * *}$ & $-0.39^{* * *}$ & $-0.51^{* * *}$ & 1 \\
\hline
\end{tabular}

$* * *=\mathrm{p} \leq 0.001$

\section{Discussion}

This study assessed cassava cultivars on 150 cassava farms from eastern Uganda (Bukedea and Kumi districts), which is the major cassava producing area (UBOS, 2017). Results showed that the farmers growing cassava in Bukedea and Kumi districts preferred NASE 03 cultivar (released in 1993) followed by NASE 14 (released in 2011) while NASE 19 (released in 2011) and NAROCASS 1 (released in 2015) were the least preferred. These findings are in agreement with observations by Kawuki et al. (2017) who also noted that NASE 03 and NASE 14 cultivars were the most predominant in eastern Uganda. Preference for NASE 03 and NASE 14 cultivars by farmers was determined by a number of attributes that the cultivars possess (Table 1) which include; sweet taste, good cooking quality, high yielding, very early maturing, good marketability, good storability in the ground and tolerance to diseases among others (Nakabonge et al., 2017). NAROCASS 1 variety was the least preferred and yet among the recently released improved cultivars with increased disease tolerance. No doubt suggesting the need 
for multi trait breeding to introgress attributes like sweet taste, good cooking quality, good marketability among others in newly released improved cassava cultivars to result in a trait balance, suiting the end beneficiary of any breeding program, which is the farmer. The top four attributes based on percentage preference according to the farmers were; sweet taste, high yields, good storability and disease resistance, in that order. The preferred cultivars however, showed susceptibility to major cassava viral diseases. This showed high regard for produce quality rather than production benefits and indicated that farmers may have limited information on effects of viral diseases on cassava, let alone their most preferred attributes.

Symptoms characteristic of CBSD and CMD were observed on farmers' cassava cultivars during this study indicating the presence of CBSD and CMD in eastern Uganda. The high incidence of both viruses among the preferred cultivars (Table3) in both districts indicated that the two diseases were still important in the region. The high prevalence of CBSD and CMD could be due to the distribution of the common vector, whitefly. Bukedea and Kumi districts are at a low altitude characterized by conditions that favor high multiplication of whiteflies, which are the vectors for CBSV and CMV (Jeremiah et al., 2015, Mwila et al., 2018). Other researchers have also correlated high CBSD prevalence to high whitefly numbers and evidence suggests that white fly, $B$. tabaci has changed and has become better adapted to cassava grown in environmental conditions prevalent at this altitude (Jeremiah et al., 2015; Mwila et al., 2018). Additionally, Alicai et al. (2007) observed that the re-emergence of CBSD in Uganda coincided with generally high whitefly populations in areas where CBSD was highly prevalent. Furthermore, the periods of spread of CBSD at coastal Tanzania closely coincided with surges in whitefly populations (Maruthi et al., 2005). Therefore, whiteflies may be responsible for the high prevalence of CBSD and CMD in eastern Uganda.

However, some researchers have considered transmission by whiteflies to be low (Hillocks et al., 2001). Therefore, the other possible reason for the high CBSD and CMD prevalence in eastern Uganda is the high rate of exchange of planting materials among farmers without due consideration of the disease status of the planting materials. Since cassava is a clonally propagated crop, the exchange of planting material across cassava growing regions contributes significantly to virus accumulation and dissemination leading to high disease incidence (Legg et al., 2015; Kawuki et al., 2016; Nakabonge et al., 2017). In addition, farmers' preference for the sweet yet susceptible cultivars showed the need for continuous supply of clean planting material of the preferred cultivars while a more permanent solution is sought for. This is because cyclic-propagation of farmer field sourced cassava cuttings that are not obtained from clean planting material sourced from seed multiplication blocks that are $250 \mathrm{~m}$ away from other cassava fields leads to continuous virus presence and build up in the environment (Maruthi et al., 2005; Kasule et al., 2020).

There was significant negative correlation among cassava cultivars preferred and CBSD/CMD severity and incidence. NASE 03 was found to have more prevalence of and most susceptible to CBSD and CMD, yet the variety was most preferred by the farmers. Meanwhile NAROCASS 1 was found most resistant to the two diseases and yet was among the least preferred by farmers. Our findings indicated that farmers preferred sweet and high starch taste qualities which may be linked to pathogen presence and spread culminating in disease incidence and severity. The sweet varieties were more susceptible to CBSV and CMV infections than the bitter varieties documented by Okpara et al. (2014) and Nakabonge et al. (2017). The findings support those of Nakabonge et al. (2017), where preference for cultivars was determined by a number of factors including sweet taste, good cooking quality, high yielding, early maturing, high marketability, good storability in the ground and tolerance to diseases among others.

Furthermore, the susceptibility of popular cultivars to major viral diseases showed that farmers lacked accurate information on the symptoms, causes, spread and management of the cassava viruses and this could exacerbate the virus prevalence in susceptible cultivars (Alicai et al., 2007). This could also explain why disease resistance is lower among the top preferred attributes. NAROCASS 1 is a relatively new released cassava cultivar with excellent disease resistance and this explains the low disease prevalence observed for this cultivar. The low disease prevalence for NAROCASS 1 was also observed by Mukiibi et al. (2019). It is prudent that much attention should be given to this cultivar to improve its other attributes and avail it to farmers but also that reassessments on the variety are made to show its stability. In addition, both CBSD and CMD incidences were highest in Bukedea than Kumi probably because many farmers in Bukedea were growing the CBSD and CMD susceptible cultivar NASE 03. On the other hand, CBSD prevalence was found to be higher than that of CMD in the districts sampled in eastern Uganda. This difference could be because the spread of CBSV and CMV in cassava depends on the cultivar and virus or virus strain (Alicai et al. 2007, 2016). Also genotype by environment interactions coupled with difference in number of whiteflies led to differential viral disease prevalence in eastern Uganda (Jeremiah et al., 2015; Mwila et al., 2018). 
Furthermore, average CBSD and CMD prevalence varied among cassava cultivars and these were consistent with those reported in other studies by Kawuki et al. (2017). This was because the farmers' cassava fields were found close to each other increasing the failure to prevent vectors from spreading the viruses. According to Kasule et al. (2020) cassava fields located in areas that are hotspots for CBSD and CMD and with a high whitefly infestation should be $250 \mathrm{~m}$. In cognizant of these challenges farmers face, breeding still remains as a top priority in cultivar improvement. The observed variations in CBSD and CMD prevalence among cassava cultivars could be because of the remarkable progress in genetic improvement of cassava for disease resistance (Kawuki et al., 2016).

\section{Conclusions}

The study reports that NASE 03 and NASE 14 cassava cultivars were the most predominant in studied districts of eastern Uganda. This showed that farmers have adopted improved varieties from breeding programs. However, NASE 03 which was found to be the most preferred due to its sweet taste and high yields, was also found to be the most susceptible to CBSD and CMD, implying that it is beyond disease resistance when farmers select cassava cultivars for planting in eastern Uganda. The more recently released NAROCASS 1 variety was the least preferred and yet had the least prevalence of CBSD and CMD. Although this illustrates the remarkable progress in genetic improvement of cassava for disease resistance, it is recommended that other farmer preferred attributes be incorporated in such improved varieties through multi trait breeding to improve on farmers' adoption.

\section{Acknowledgement}

The authors are grateful to the Regional Universities Forum for Capacity Building in Agriculture (RUFORUM) for funding this research through the cassava Community Action Research Programmes Plus (CARP+). We thank the farmers of Kumi and Bukedea districts of eastern Uganda who participated in this study.

\section{Conflict of Interest}

The authors declare that they have no conflict of interest.

\section{References}

Alicai, T., Ndunguru, J., Sseruwagi, P., Tairo, F., Okao-Okuja, G., Nanvubya, R., Kiiza, L., Kubatko, L., Kehoe, M. A., \& Boykin, L. M. (2016). Cassava brown streak virus has a rapidly evolving genome: implications for virus speciation, variability, diagnosis and host resistance. Scientific Reports, 6, 36164. Https://doi.org/10.1038/srep36164

Alicai, T., Omongo, C. A., Maruthi, M. N., Hillocks, R. J., Baguma, Y., Kawuki, R., Bua, A., Otim-Nape, G. W., \& Colvin, J. (2007). Re-emergence of cassava brown streak disease in Uganda. Plant Disease, 91, 24-29. https://doi.org/10.10 94/PD-91-0024

FAOSTAT. (2017). FAO database. Food and Agriculture Organization of the United Nations, Rome, Italy. Retrieved from http://www.fao.org/faostat/en/\#data/QC.

Gondwe, F. M. T., Mahungu, N. M., Hillocks, R. J., Moyo, C. C., Soko, M. M., \& Benesi, I. R. M. (2003). Economic losses experienced by small-scale farmers in Malawi due to cassava brown streak virus. In: Legg, J.P., Hillocks, R.J. (Eds.), Cassava Brown Streak Disease: Past, Present and Future (pp.28-35). Proceedings of an International Workshop, Mombasa, Kenya, 20-30 October 2002. National Resources International Limited, Aylesford, UK, pp. 28-38. http://www.cpp.uk.com

Hillocks, R. J., Raya, M. D., Mtunda, K., \& Kiozia, H. (2001). Effect of brown streak virus disease on yield and quality of cassava in Tanzania. Journal of Phytopathology, 149, 389-394. https://doi.org/10.1111/j.1439-043 4. 2001.tb03868.x

International Institute of Tropical Agriculture (IITA). (1990). Cassava in Tropical Africa: A reference manual. Ibadan, Nigeria. pp. 61-63. Retrieved from https://newint.iita.org/wp-content/uploads/2016/06

Jeremiah, S. C., Ndyetabula, I. L., Mkamilo, G. S., Haji, S., Muhanna, M. M., Chuwa, C., Kasele, S., Bouwmeester, H., Ijumba, J. N., \& Legg, J. P. (2015). The Dynamics and Environmental Influence on Interactions Between Cassava Brown Streak Disease and the Whitefly, Bemisia tabaci. Journal of Phytopathology, 105, 646-655. http://dx.doi.org/10.1094/PHYTO-05-14-0146-R

Kasule, F., Wasswa, P., Mukasa, S.B., Okiror, A. and Mwang'ombe, A.W. (2020). Effective isolation distance for prevention of cassava virus infections in Uganda. African Crop Science Journal, 28, 1-13. https://dx.doi.org/10.4314/acsj.v28i1.1S

Kawuki, R. S., Adiga, G., Orone, J., Alicai, T., Edimu, M., Omara, T., Pariyo, A., Esuma, W., Omongo, C., Bua, A., Kanju, E., \& Baguma, Y. (2017). Limits of phytosanitation and host plant resistance towards the control 
of cassava viruses in Uganda. African Journal of Rural Development, 2, 455-466. Retrieved from http://www.afjrd.org/jos/index.php/afjrd/article/view/193

Kawuki, R. S., Kaweesi, T., Esuma, E., Pariyo, A., Kayondo, S. I., Ozimati, A., ... Baguma, Y. (2016). Eleven years of breeding efforts to combat cassava brown streak disease. Breeding Science Preview, 66, 560-571. http://doi.org/10.1270/jsbbs.16005

Legg, J. P., Jeremiah, S. C., Obiero, H. M., Maruthi, M. N., Ndyetabula, I., Okao-Okuja, G., ... Lava, K. P. (2011). Comparing the regional epidemiology of the cassava mosaic and cassava brown streak virus pandemics in Africa. Virus Research, 159, 161-170. http://doi.org/10.1016/j.virusres.2011.04.018

Legg, J. P., Lava Kumar, P., Makeshkumar, T., Tripathi, L., Ferguson, M., Kanju, E., Ntawuruhunga, P., \& Cuellar, W. (2015). Cassava virus diseases: biology, epidemiology, and management. In Loebenstein, Gad, Katis, Nikolaos I. (Eds.), Advances in Virus Research, 91, 85-142. http://dx.doi.org/10.1016/bs.aivir.2014.10.001

Legg, J. P., Somado, E. A., Barker, I., Beach, L., Ceballos, H., Cuellar, W. ... Fauquet, C. (2014). A global alliance declaring war on cassava viruses in Africa. Food Security, 6, 231-248. http://doi.org/10.1007/s12571-0140340-x

Maruthi, M. N., Hillocks, R. J., Mtunda, K., Raya, M. D., Muhanna, M., Kiozia, H. ... Thresh, J. M. (2005). Transmission of Cassava brown streak virus by Bemisia tabaci (Gennadius). Journal of Phytopathology, 153, 307-312. https://doi.org/10.1111/j.1439-0434.2005.00974.x

McQuaid, C. F., Sseruwagi, P., Pariyo, A., \& Boscha, F. (2016). Cassava brown streak disease and the sustainability of a clean seed system. Plant Pathology, 65, 299-309. http://doi.org/10.1111/ppa.12453

Mukiibi, D. R., Alicai, T., Kawuki, R., Okao-Okuja, G., Tairo, F., Sseruwagi, P., Ndunguru, J., \& Ateka, E. M. (2019). Resistance of advanced cassava breeding clones to infection by major viruses in Uganda. Crop Protection, 115, 104-112. https://doi.org/10.1016/j.cropro.2018. 09.015

Mwila, N., Nuwamanya, E., Odong, T. L., Badji, A., Agbahoungba, S., Ibanda, P. A., Mwala, M., Kyamanywa, S., \& Rubaihayo, P. R. (2018). Genotype by environment interaction unravels influence on secondary metabolite quality in cassava infested by Bemisia tabaci. Canadian Journal of Agriculture Science, 8, 1-18. https://doi.org/10.5539/jas.v10n8p192

Nakabonge, G., Samukoya, C., \& Baguma, Y. (2017). Local varieties of cassava: Conservation, cultivation and use in Uganda. Environment, Development and Sustainability. https://doi.org/10.1007/s10668-017-9997-6

Okpara, D. A., Mbah, E. U., \& Chukwu1, E. I. (2014). Assessment of growth and yield of some high-and lowcyanide cassava genotypes in acid ultisols of south eastern Nigeria. African Journal of Biotechnology, 13, 651-656. https://doi.org/10.5897/AJN2013.13200

Sseruwagi, P., Sserubombwe, W. S., Legg, J. P., Ndunguru, J., \& Tresh, J. M. (2004). Methods of surveying the incidence and severity of cassava mosaic disease and whitefly vector populations on cassava in Africa: a review. Virus Research, 100, 129-142. http://doi.org/10.1016/j.virusres.2003.12.021

UBOS. (2017). Uganda Bureau of Statistics 2017 Statistical Abstract. Ministry of Finance, Planning and Economic Development, Government of Uganda. Retrieved from https://www.ubos.org.2017.statistical

\section{Copyrights}

Copyright for this article is retained by the author(s), with first publication rights granted to the journal. This is an open-access article distributed under the terms and conditions of the Creative Commons Attribution license (http://creativecommons.org/licenses/by/4.0/). 